Western University

Scholarship@Western

Aboriginal Policy Research Consortium International (APRCi)

1997

\title{
Teaching Research to Aboriginal Students
}

Grant Larson

Leslie Brown

Follow this and additional works at: https://ir.lib.uwo.ca/aprci

Part of the Social Work Commons

Citation of this paper:

Larson, Grant and Brown, Leslie, "Teaching Research to Aboriginal Students" (1997). Aboriginal Policy Research Consortium International (APRCi). 264.

https://ir.lib.uwo.ca/aprci/264 
This article was downloaded by:

[University of Western Ontario]

On: 09 December 2012, At: 07:25

Publisher: Routledge

Informa Ltd Registered in England and Wales Registered Number: 1072954

Registered office: Mortimer House, 37-41 Mortimer Street, London W1T 3J H, UK
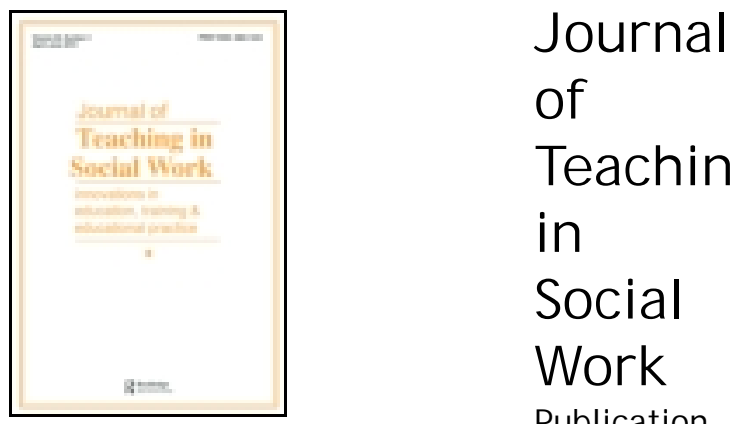

Teaching

in

Social

Work

Publication

details,

including

instructions

for authors

and 
subscription information:

http://

www. tandfonline

loi/ wtsw20

Teaching

Research

to

Aboriginal

Students

Grant Larson

DSW ${ }^{a} \&$

Leslie Brown

MPA ${ }^{b}$

a University

College of

the Cariboo,

Kamloops,

British

Columbia,

Canada 
${ }^{\mathrm{b}}$ University of Victoria, Victoria, British

Columbia,

Canada Version of record first published:

13 Oct 2008.

\section{To cite this article: Grant Larson DSW \&} Leslie Brown MPA (1997): Teaching Research to Aboriginal Students, J ournal of Teaching in Social Work, 15:1-2, 205-215

\section{To link to this article: http://}

dx. doi. org/ 10.1300/ J 067v15n01_14

\section{PLEASE SCROLL DOWN FOR ARTICLE}

Full terms and conditions of use: http:// www.tandfonline.com/page/terms-andconditions 
This article may be used for research, teaching, and private study purposes. Any substantial or systematic reproduction, redistribution, reselling, loan, sub-licensing, systematic supply, or distribution in any form to anyone is expressly forbidden.

The publisher does not give any warranty express or implied or make any representation that the contents will be complete or accurate or up to date. The accuracy of any instructions, formulae, and drug doses should be independently verified with primary sources. The publisher shall not be liable for any loss, actions, claims, proceedings, demand, or costs or damages whatsoever or howsoever caused arising directly or indirectly in connection with or arising out of the use of this material. 


\title{
Teaching Research to Aboriginal Students
}

\author{
Grant Larson \\ Leslie Brown
}

\begin{abstract}
Authentic education is not carried on by " $A$ " for " $B$ " or by " $A$ " about " $B$ " but rather by " $A$ " with " $B$."
\end{abstract}

-Paulo Freire (1970)

\section{INTRODUCTION}

The issue addressed in this paper concerns the challenge for Canadian social work educators in teaching research methods to undergraduate aboriginal students in ways that respect cultural context, are anti-racist and empowering. This becomes a special challenge in situations where the teachers are white and the students are aboriginal. In our experience, social work students often come to their first research courses with mind sets or perspectives about the course which have been based on previous experiences, understandings and attitudes (sometimes negative given an association with statistics). Research teachers also bring their particular perspectives on course content, the students, and how the course is to be taught. These perspectives of students and teachers set the stage for not only what happens in the learning situation but also for the learning that students take from the course to their real worlds. The mind sets of teachers and students may pose barriers to learning in monocultural-cultural learning situations but are particularly exacerbated when white teachers from the dominant society facilitate the learning for aboriginal students.

The following paper does not attempt to prescribe "how" one is to teach aboriginal students, and it does not compare aboriginal and non-ab-

Grant Larson, DSW, is Associate Dean of Social Work, University College of the Cariboo, Kamloops, British Columbia, Canada. Leslie Brown, MPA, is Assistant Professor of Social Work, University of Victoria, Victoria, British Columbia, Canada. 
original students. Such topics would, in fact, tend to perpetuate the myth of the white expert teacher, reinforce the dominance of the oppressors, and dehumanize the teaching process. These ideas become the very antithesis of the major themes presented in the paper. Instead, the paper explores some of the important issues for both students and teachers in this crosscultural teaching endeavor and presents a reframing of the enterprise of teaching a particular course, research methods.

The authors believe that the goals of teaching research to aboriginal students are the development of knowledgeable and competent consumers, practitioners and participants of research. These goals involve cognitive, behavioral and attitudinal changes so that aboriginal students may be liberated from the reality of oppression. For aboriginal people to effectively critique the research that is being done in their communities, they need to understand how the mainstream culture constructs the concepts and processes of research. Freire (1970) suggests that this type of education makes oppression and its causes known to the oppressed, and becomes the necessary ingredient in the struggle for liberation. Further, in order to conduct useful and non-oppressive research in their communities, aboriginal people need to develop appropriate and relevant research skills.

The aim of the teacher then is to make visible the research process within its cultural and political contexts and to provide opportunities for students to develop those research skills that will effectively assist them in reaching their personal, professional and community goals. The challenge for the teacher is to develop not only course content specific to these goals, but an empowering process which is consistent with social work philosophy.

\section{HISTORICAL BACKGROUND}

The aboriginal peoples of Canada come from a diverse array of cultural backgrounds. There are many, many groups of aboriginal peoples (termed First Nations) in Canada, each with its own language, spirituality, values and economic/political organizations. There are 53 aboriginal languages in Canada (Mercredi and Turpel, 1993) and 592 Indian bands (Frideres, 1988). Even within relatively small geographic areas of the country, very different cultural Nations can be found. (For example, Vancouver Island is a small island off the west coast of Canada which is home to three very distinct First Nations; the Kwakwaka Wakw, Nuu-Chah-Nulth, and the Coast Salish peoples.) Although First Nations people in Canada have been divided by geographic boundaries, cultural differences and at times legal distinctions, the history of aboriginal-white relations has generally ignored their diversity. 
The colonization of Canada by European whites is exemplified by the Indian Act of 1876 (most recently revised in 1989). This paternalistic piece of legislation, which defines designated aboriginal people as "Indian," established specific parcels of land as reserved for "Indians" and has exerted control over the political and economic aspects of the lives of aboriginal people living on reserves (Frideres, 1988). The goal of the white Canadian government was to "civilize," protect and Christianize aboriginal peoples and to incorporate them in Canadian society. This policy of assimilation has been resisted by aboriginal peoples and they continue to express their inherent rights and privileges as First Nations. Frideres (1988) has suggested that although the Indian Act was administered in the interest of benign rule it has created isolation, control, enforced poverty and has denied First Nations equality in any realm of Canadian life.

A part of the history of the relationship between aboriginal and white people has been the conduct and use of research on almost every aspect of aboriginal peoples' lives. As one aboriginal student noted, "we have been studied to death." Anthropologists have had a heyday in learning about aboriginal cultures. Franz Boaz, for example, made his renowned reputation on the backs of aboriginal culture (see for example, Boaz, 1897). The museums of the world are filled with the "artifacts" he and others have collected, or as some aboriginal people describe it, these museums are filled with their family possessions which were stolen. Sociologists, educators, social workers and others have not done much better. Aboriginal people in Canada are quite familiar with the "visiting researcher" who flies into their community, collects data and then disappears. Aboriginal people have been the objects of study, yet seldom have they received benefits that reflect the findings from these studies (Morrissette, McKenzie and Morrissette, 1993).

Not only has there been a lack of benefits from research on aboriginal people, but the information collected and the theories generated from the research have, in fact, been used to develop racist policies and practices. More and more, oppressors use science and technology as unquestionably powerful instruments to serve their purposes (Freire, 1970). For example, Comeau and Santin (1990) describe the fact that many First Nations communities across Canada lost an entire generation of children to the custody of provincial child welfare agencies in the 1960 s and 70 s. Child welfare policy and practice that resulted in this cultural genocide of First Nations people was based to a large extent on white researchers' study of aboriginal families and children. Another example illustrates how data on aboriginal peoples have been collected and misused. Based on anecdotal research, not 
generalizable to all aboriginal peoples, social workers encountered by one of the authors were being taught particular communication skills for working with aboriginal peoples. "Never look them in the eye," was the message. The assumption that all aboriginal peoples (as diverse as they are in language and culture) would regard eye contact in all situations as disrespectful is absurd . . . yet such ideas that create stereotypes of aboriginal people persist and continue to be used by some social work practitioners.

Social work policy and practice with aboriginal people in Canada has to a large extent been based on research by the dominant white society. This research has been integral to the oppression and control of aboriginal peoples, and therefore research activities are suspect to aboriginal peoples. Because of this historical experience, aboriginal students often come to a course on social work research with an inherent mistrust. These students have their own individual stories of the experience of white researchers investigating sexual abuse, alcoholism or suicide in their communities-of digging up painful and private experiences and then leaving the community to "publish" the results or create policies and programs on their behalf. These students have a justifiable mistrust of the content and process of research, and also of us, white researchers and educators.

Given the history of oppression and the use of research in that oppression, one might be left asking the question about whether there should be any role for white instructors in teaching aboriginal students, and particularly in teaching them research. The white teacher-aboriginal students situation represents an obvious example of the opportunity differences between white and aboriginal peoples. Do white instructors simply reinforce the system of oppression by the dominant white society? How does this happen? Do, and how do, they teach others to oppress the way they have oppressed? Do, and how do, they indoctrinate the oppressed to adapt to the world of oppression? Do, and how do, white teachers invade the cultural context of others with little respect for their potential? These are, in fact, the very questions we believe need discussion and personal exploration by white instructors.

\section{PERSONAL CONTEXT OF THE RESEARCH TEACHERS}

Given the impact that the teacher may have on the learning situation it is important to explain the personal context of this paper's authors. Both of us are white middle-class faculty members in accredited schools of social work that have predominantly white middle class students. One is female and one is male. We both have had very positive experiences in teaching and conducting research. Relationships with aboriginal peoples have been 
positive and each has had the desire and motivation to learn about First Nations, to teach cross-culturally, and to further develop abilities as instructors and researchers. Both of us come from a structural feminist perspective. Yet, when invited by aboriginal people associated with outreach programs to teach research to aboriginal students, we each experienced feelings of fear and inadequacy. These emotional responses may have arisen partly from the questions we have had about our professional abilities to teach research cross-culturally in ways that would not perpetuate assimilationist and oppressive attitudes.

Freire (1970) has suggested that both the oppressed and the oppressor are manifestations of dehumanization and that each has been submerged in the reality of oppression. Our apprehension about teaching all aboriginal classes may have resulted from our awareness of the symbolic role of oppressors that we are to aboriginal students. We are both white, well-educated, successful in our professional careers, and integrated and accepted by the dominant society. We, no doubt, symbolize the power of the oppressor to aboriginal students and fear that we present a psychological barrier to the achievement of the personal and community goals of aboriginal students.

\section{REFRAMING THE APPROACH TO TEACHING}

The work of Paulo Freire provides a useful framework for exploring effective approaches to teaching aboriginal students. Within this framework of education for liberation, the work of Malcolm Knowles is also helpful in considering the classroom experience. Although the context and purpose of the works of Freire and Knowles differ substantially, both present concepts that speak well to the experience of the current authors. Knowle's purpose is far from the politically liberating purpose of Freire but he suggests, like Freire, that effective teaching situations break down the traditional student-teacher roles, are collaborative, and are based in real life experiences. Shor and Freire (1987, p. 10) explicate how traditional lecture-based passive curriculum is not simply poor pedagogical practice but is the teaching model most compatible with promoting the dominant authority in society and with disempowering students. "No pedagogy which is truly liberating can remain distant from the oppressed by treating them as unfortunates and by presenting for their emulation models from among the oppressors" (Freire 1970, p. 39). Both the approaches of Freire and Knowles reflect a sharing of power between instructor and students where the instructor becomes a facilitator of students' self-directedness and where learning is built upon a reservoir of personal experience.

The classroom is an artificially constructed environment. Traditionally 
we have learned about student and teacher roles through our socialization experiences in earlier educational systems. We have learned to partialize our lives and to take on the student or teacher role when we enter the classroom. Freire (1970) asserts that the traditional teacher talks about reality as if it were motionless, static, compartmentalized and predictable. Knowles (1980) describes the learning in traditional pedagogical approaches as a process dependent on the teacher for structure and direction to acquire subject-matter which does not rely upon, nor is connected with, the learner's past experience. Learners are encouraged to leave their outof-class experience behind and follow a step-by-step progression directed by the teacher. In spite of social work's emphasis on the "person in the environment," the current authors became acutely aware of their subtle socialization to elements of this pedagogical approach during the experience of teaching all aboriginal classes.

The teaching environment of an all aboriginal class takes on a unique quality in this regard. In the experience of the authors, aboriginal students are not merely students in a class, but come to the class and assert themselves as whole people-as mothers, children, workers, cultural people, spiritual people with a wealth of current and past experience. There is an expectation that teachers also enter the classroom environment as whole people. No one is expected, in the way they think or act, to leave a part of themselves outside the door of the classroom. The relationship between people in the classroom becomes the critical element in the teaching and learning endeavor. Freire's work supports this concept and indicates that to be effective, teachers must act in solidarity with the oppressed. Teachers must regard aboriginal students as persons, not as an abstract category-"students." As with all relationships, this kind of student-teacher relationship takes time to develop and nurture.

Of particular importance in teaching aboriginal students is the recognition of the diversity of First Nations from which students come. These Nations have a history of relations with each other that can affect the classroom environment. For example, the three Nations on Vancouver Island referred to earlier have a history of war and trade with one another. Their histories have occasionally created a competitive and even distrustful atmosphere in the classroom. As teachers we have been reminded that aboriginal students are not "generic." Recognition of the difference in Nations is important, however they do have the common experience as aboriginal peoples in their relationships to Canada and non-aboriginal people upon which to build a community learning experience.

Traditionally, the confines of a course (time, predetermined objectives, content, and agendas) restrict relationship building. Our experience with 
aboriginal students suggests that an extensive amount of time needs to be devoted to developing relationships and in getting "to know who each other is" apart from the academic agenda. This is not lost or wasted time but rather part of the process of developing a collaborative partnership and a way of connecting course content with the personal lives of students. In a sense then, the teaching enterprise with aboriginal students breaks down the traditional roles of student and teacher. As Freire suggested, the teacher relearns the material with the students. Such a relationship between teachers and students is consistent with empowerment concepts of social work practice. Rose (1990, p. 49) indicated that empowerment is "a process of dialogue through which the client is continuously supported to produce the range of possibilities that she/he sees appropriate to his/her needs; that the client is the centre for all decisions that affect her/his life." Empowerment then, is not about giving power as a commodity to a client or student, but is about building and nurturing relationships between people that understand and struggle with issues of power. In the classroom then, power and relationships become major themes in the course.

The specific teaching strategies used in the classroom must, therefore, be consistent with the relationship elements and power dynamics previously discussed. First, in order to maximize these components, class sizes must be relatively small (12-20). Larger classes are not conducive to the building of empowering relationships (Sheafor et al., 1994). Also, relationships are not confined to the hours in the classroom. There is a heightened awareness of the need for accessibility and availability of instructors outside of the class.

We have learned to make our teaching processes explicit, to share the responsibility for the teaching strategies with class participants. For instance, students are emphatic that they want the course to be equivalent to that of mainstream students. They want assurance that the standards will not be watered down. Class discussion on the paternalism inherent in making the standards lower for aboriginal students is a key piece of this course. As one student stated, "don't do us any favors!" The discussion becomes quite complex, however, as the need for flexibility, to respect the particular learning needs, process, and timing of the class (rather than ours), has to be accommodated without expanding the course beyond the workload of a mainstream social work course. Extending or "enriching" courses in this manner would, in fact, create another barrier to the empowerment of aboriginal students.

Methods of evaluation and grading criteria are also a part of the class discussion on power and its affect on relationships. Again, openness and flexibility serve us best as teachers. Maintaining a relationship through 
assignments has also proven helpful. That is, enabling students to draft assignments for comments throughout the course in effect uses the assignment as a piece of correspondence between student and teacher in which each can learn and teach the other. Freire (1970, p. 67) referred to dialogue of this type as the process whereby the "teacher-of-the-student" and the "student-of-the-teacher" concepts cease to exist and both assume joint responsibility for a process for all to grow. Balancing standards of writing, grammar and technical skills with that of political awareness and critical thought is a tension that is explored with students. Generally speaking, engaging in dialogue with students around assignments, evaluation and all other components of the teaching enterprise is critical to the relationship focused approach.

\section{REFRAMING THE CONCEPT OF RESEARCH}

While reframing the teaching approach is fundamental to the task of teaching research to aboriginal students, our experience suggests that the central content of the course, the concept of research, also benefits from reframing.

Research is reknowing what we thought we knew (Shor and Freire, 1987), but as Bobby Joseph, an aboriginal elder explained to one of us, for aboriginal people it is reknowing what they know in a way that white people can understand. Research, as has been generally practiced in First Nations communities then, is a means of communication. It is a political tool rather than, as commonly viewed in white Canadian culture, a way of knowing.

Research is a form of literacy (Kirby and McKenna, 1989). As such, it enables oppressed peoples to engage in mainstream life and systems. It must also, however, be accompanied with an understanding of the social context within which it operates. Kirby and McKenna indicate that research that does not reflect on and analyze the social context from which it springs, serves only the status quo and does not enable us to interact with and change society. Similarly, the teaching of research needs to be contextualized with the social realities of aboriginal peoples. The need to acknowledge research as a culturally-based way of knowing is therefore heightened. Placing it, as a concept, within the socialization of mainstream thinking begins to demystify its use as a tool of oppression.

The majority of research done in aboriginal communities is still dominated by a positivistic paradigm. Therefore it is important that aboriginal students be able to understand and critically analyze such methods. As 
well, they may be able to effectively use such methods to further goals of self-determination.

The specific content of the course, therefore, may on the surface look similar to other research courses. It includes positivistic as well as feminist and structural methodologies. Regardless of the specific paradigms and methods included in any particular class, what is distinctive is that students are taught to engage in ongoing critique of the content from an emancipatory standpoint.

Hartsock (1983) suggests that an emancipatory standpoint assumes that our understanding of reality is constructed by our specific life experiences. Knowledge therefore is not objectively created but influenced by our gender, race and class. Riessman (1993) urges students to consider how their standpoint influences what they see. She defines standpoint as their class and status position, race, gender and theoretical persuasion. Taking an emancipatory standpoint in the classroom then means that issues of oppression, such as racism, may enter the research process at every or any stage. Once the notion of standpoint is understood, the structures of oppression are illuminated for students. Thus, providing a starting point for liberatory struggle.

Laurie Gilchrist (1994, p. 62) explains the struggle of aboriginal peoples, "to decolonize ourselves and our knowledge production. We need to change research method(s) to end the voyeurism of our communities into action based knowledge that is useful on the road to self-determination. We need to recognize and forge ahead with our own paradigms of theory, research method and practice, even as we engage in mainstream critical research."

While teaching mainstream research skills continues to be recognized as important at the undergraduate level, there is growing interest among aboriginal students in interpretative paradigms. Approaches such as phenomenology (see for example, Reissman, 1993), institutional ethnography (D. Smith, 1987) and feminist action research (Kirby and McKenna, 1989) offer students alternatives to traditional methods and, by example, encourage the creation of new approaches to the construction of knowledge.

For the aboriginal students in our classes, learning research means learning strategies and tools that can support the self-determination activities of their communities. The desire of aboriginal students to learn ways to make research work as a community development technique illustrate the political, transformational practice aspects of research. Such a framework for learning about research methods informs both what specific techniques and methodologies are taught and how such techniques are critically examined. 


\section{CONCLUSION}

Teaching research to aboriginal students is a political act. As white academics, what and how we teach can unwittingly assist in the assimilation process in that they facilitate the internalization of white values by aboriginal students. "(It is a) false assumption that the goal of academic freedom is best served by political neutrality (failing to challenge dominant structures), by teaching methods that belie the reality that our very choice of subject matter, manner and style of presentation embodies ideological and political signifiers .. (of white domination)" (bell hooks, 1988). Our goal in teaching research is to make a tool of the oppressors, research methods, explicit. In so doing, we also make the act of teaching and the power inherent in that role explicit. We strive to make visible our socialization as instructors and how that impacts our teaching methods, our approach to the content and our interactions with aboriginal peoples. This is a challenge, however, with which we are still uneasy.

Earlier in the paper we posed questions about whether there is a role for white academics in teaching research to aboriginal students, and if so, how that activity impacts aboriginal people. Having taught several classes of aboriginal students we do believe that we, as white instructors, subtly reinforce a system of oppression. However, by struggling to understand and make explicit HOW we do this, and by discussing the topic of power and oppression with students, we hope to be the kind of white instructors who work in solidarity with aboriginal peoples working for self-determination. Freire (1970) has indicated that those who authentically commit themselves to the people must re-examine themselves constantly as they unknowingly bring the oppressor with them. We recognize how important it is to remain uncomfortable with the challenge, and to continually review and critique our teaching. As this is difficult to do individually or in isolation from other teachers, we emphasize the importance and necessity of white instructors challenging each other. This is essential in our experience in helping each other to stop from falling into the trap of expert, of explaining "how to" teach aboriginal students. Also, we recognize the need to check our assumptions and learning with the reality of aboriginal life. We continually invite dialogue with aboriginal people to assist our personal and professional development.

And finally, we have learned that the experience of teaching classes of all aboriginal students has reawakened a critical awareness of our teaching of mainstream courses and students. Isn't it just as important to teach about power and research to the oppressors as to the oppressed? The liberation of the oppressed is the liberation of people, not things, and the oppressor also becomes liberated in the process (Freire, 1970). 


\section{REFERENCES}

Boas, Franz. (1897). "The Social Organization and Secret Societies of the Chattily Indians," United States National Museum Report for 1895: 311-788.

Comeau, Pauline and Santin, Aldo. (1990). The First Canadians-A Profile of Canada's Native Peoples Today. Toronto: James Lorimer \& Co.

Freire, Paul. (1970). Pedagogy of the Oppressed. New York: Continuum.

Frideres, James. (1988). Native Peoples in Canada Contemporary Conflicts, Third Edition. Scarborough: Prentice-Hall Canada.

Gilchrist, Laurie. (1994, March). Aboriginal Communities and Social Science Research: Voyeurism in Transition. Paper presented to the Wunska Conference, Chase, B.C., Canada.

Hartsock, Nancy. (1983). "The Feminist Standpoint: Developing the Ground for Specifically Feminist Historical Materialism." In S. Harding and M. Hintikka (Eds.), Discovering Reality: Feminist Perspectives on Epistemology, Methodology and Philosophy of Science. Dordrecht: Reidel.

hooks, bell. (1989). Talking Back: Thinking Feminist, Thinking Black. Toronto: Between the Lines.

Kirby, Sandra and McKenna, Kate. (1989). Experience, Research, Social Change: Methods from the Margins. Toronto: Garamond Press.

Knowles, Malcolm. (1980). The Modern Practice of Adult Education: From Pedagogy to Andragogy. New York: Cambridge, The Adult Education Company.

Mercredi, Ovid and Turpel, Mary Ellen. (1993). In the Rapids: Navigating the Future of First Nations. Toronto: Penquin Books.

Morrissette, Vern, Morrissette, Larry and McKenzie, Brad. (1993). "Towards an Aboriginal Model of Social Work Practice," Canadian Social Work Review, $10(1), 91-108$.

Riessman, Catherine. (1993). "Teaching Research: Beyond the Storybook Image of Positivist Science." In Joan Laird (Ed.), Revisioning Social Work Education: A Social Constructionist Approach. New York: The Haworth Press, Inc.

Rose, Stephen. (1990). "Advocacy/empowerment: An Approach to Clinical Practice for Social Work." Journal of Sociology and Social Welfare, 17(2), 41-5I.

Sheafor, B.W., Horejsi, C.R., and Horejsi, G.A. (1990). Techniques and Guidelines for Social Work Practice (3rd ed.). Toronto: Allyn and Bacon.

Shor, I. and Freire, P. (1987). Pedagogy for Liberation. West Port, Connecticut: Bergin and Garvey.

Smith, Dorothy. (1987). The Everyday World as Problematic: A Feminist Sociology. Toronto: The University of Toronto Press. 